\title{
LA IMAGINACIÓN POLÍTICA DE LA INMUNIDAD. DEL "CUERPO SOCIAL" A LA "COMUNA DEL CUERPO"
}

\author{
The Political Imagination of Immunity. From the "social body" to "body's commune"
}

\author{
Miguel Ángel Martínez García* \\ * CONICET-PELCC (UNTREF) (Argentina) \\ miguemartinezgarcia@gmail.com
}

\section{Palabras clave \\ Biopolítica \\ Biomedicina \\ Inmunidad \\ Comunidad \\ Imaginación política}

\section{Keywords}

Biopolitics

Biomedice

Immunity

Community

Political imagination

\begin{abstract}
Resumen
En este artículo realizamos un análisis de dos textos literarios de Diamela Eltit: "Colonizadas" (2009) e Impuesto a la carne (2010). Para esta tarea, nos apoyamos en los desarrollos teóricos de una serie de autores fundamentales de la filosofía en las últimas décadas, como Georges Canguilhem, Michel Foucault, Donna Haraway o Roberto Esposito. En diálogo, especialmente, con la categoría de inmunidad (en tanto que categoría biopolítica) que propone este último, llegamos a la conclusión de que los textos de Eltit detectan las claves de la imaginación política de nuestra época. A partir, primero, de la imagen de un mundo convertido en hospital, en el que el (bio)poder y la (bio)medicina se confunden y ocupan todas las franjas de la vida; y a partir, en segundo lugar, de un conjunto de imágenes corporales, desde los cuerpos enfermos a la "comuna del cuerpo", las narraciones de la escritora chilena ponen en escena, en efecto, una imaginación que podríamos reconocer como la imaginación política de la inmunidad. La disposición de estas imágenes, no obstante, no solo nos ayuda a entender el modo en que dicha imaginación funcionaría (en tanto que parte de una forma específica de gobierno), sino que también nos ofrece las claves - tal es, al menos, nuestra hipótesis - para cuestionarla y transformarla. El recorrido, si seguimos la lectura de Impuesto a la carne, podría ser el que va de la imagen de un "cuerpo social" inmunizado a la imagen de una "comuna del cuerpo".
\end{abstract}

\section{Abstract}

In this paper we analize two literary texts by Diamela Eltit: "Colonizadas" (2009) and Impuesto a la carne (2010). We will base our analysis in the theoretical works of some of the most important philosophers in the last decades, such as Georges Canguilhem, Michel Foucault, Donna Haraway or Roberto Esposito. Specifically, in dialogue with the category of "immunity" (as a biopolitical category) proposed by Esposito, we will come to the conclusion that Eltit's texts point out some of the keys of the political imagination of our time. Firstly, from the image of a world turned into a hospital, in which (bio)power and (bio)medicine are mixed up and reach all the areas of life; and secondly, from an ensemble of corporal images, which go from sick bodies to the "body's commune", the narratives of the chilean writer bring to scene an imagination that could be recognized as the political imagination of immunity. These images, however, not only help us to understand the way in which this imagination work (since it comes from a specific way of governenment), but also offer us the keys - and this is our hypothesis - to question it and transform it. According to our interpretation of Impuesto a la carne, this way could be the one which leads us from the image of an immunized "social body" to the image of a "body's commune".

Martínez García, M. Á. (2018). La imaginación política de la inmunidad. Del "cuerpo social" a la "comuna del cuerpo". Papeles del CEIC. International Journal on Collective Identity Research, vol. 2018/1, papel 184, CEIC (Centro de Estudios sobre la Identidad Colectiva), UPV/EHU Press, http://dx.doi.org/10.1387/pceic.17990 


\section{INTRODUCCIÓN ${ }^{1}$}

Entre 2009 y 2010, la escritora y artista chilena Diamela Eltit publica dos textos literarios: "Colonizadas", un relato corto, e Impuesto a la carne, una novela que comparte personajes y núcleos de la trama con el relato anterior. El título en ambos textos es sumamente significativo: "Colonizadas" hace referencia a la colonización del cuerpo de dos personajes (madre e hija) por parte del cuerpo médico; Impuesto a la carne da cuenta asimismo de dicho proceso, pero va un paso más allá de él. En este último texto, no es solo que los personajes, aparentemente enfermos, se vean expropiados de su experiencia de enfermedad o de su capacidad de decisión en relación con su cuerpo en un determinado espacio hospitalario, sino que el foco se amplía y trasciende el contexto de un diagnóstico o de una situación particular de enfermedad.

En esta novela, como en "Colonizadas", encontramos a los personajes, la madre y la hija, desde el principio, en un centro médico. El texto, sin embargo, a lo largo de sus casi 200 páginas, no precisa qué tipo de centro es ni cuál ha sido el día o la causa concreta de su ingreso. No hallamos, siquiera, una previsión temporal en torno a la fecha en que podrían obtener el alta. De algún modo, parece que los personajes se hubieran resignado a permanecer un "tiempo indefinido en el hospital" (Eltit, 2010: 105). Poco a poco, no obstante, el enigma se resuelve. A medida que la acción (si podemos llamarla así) de la novela transcurre, comprendemos que aquí no se trata tanto de que el hospital en el que los personajes se encuentran constituya un mundo cerrado (como se podía intuir en el relato), sino más bien de que el mundo en el que viven se ha convertido definitivamente en un hospital. Por eso no pueden salir de él ("Ahora mismo deambulamos (...) por los bordes de un mundo que nos resulta sorprendente e invasivo", afirma la hija), porque no hay un afuera de ese "mundo enfermo" (ibídem: 11-12). La madre y la hija están sometidas, entonces, al pago de un "impuesto" obligatorio (que asumen, en efecto, con sus cuerpos: "la carne") por el simple hecho de vivir en un "territorio" constituido como una ilimitada "patria médica" (ibídem: 29).

Nuestra hipótesis es que estos textos detectan los motivos fundamentales de la imaginación política de nuestra época, y que, en consecuencia, nos advierten

\footnotetext{
${ }^{1}$ Este artículo se inscribe en el marco del Proyecto de Investigación "La imaginación política de la inmunidad. Figuraciones de la enfermedad y formas de vida en la literatura latinoamericana contemporánea", que el autor desarrolla en el Programa de Estudios Latinoamericanos Contemporáneos y Comparados (PELCC) de la Universidad Nacional de Tres de Febrero (UNTREF, Argentina) gracias a una Beca Interna Postdoctoral del Consejo Nacional de Investigaciones Científicas y Técnicas (CONICET).
} 
acerca de los ejes sobre los que se articulan las formas de gobierno actuales. En los dos títulos, las líneas argumentales, las referencias explícitas (podríamos decir foucaultianas) al "territorio" o a la "patria médica", o en otros pasajes en los que se describe la "biología" como el "instrumento verídico y apto para establecer el centro en el que radica el umbral de la historia" (Eltit, 2010: 127), no solo se delinea la estructura elemental de un mundo convertido en hospital, sino que además se sugiere, en efecto, que dicha estructura es una estructura biopolítica. Después, el hecho de que pasemos de un relato en el que parece que se tematiza el hospital como lugar de encierro (es decir, en tanto que institución biopolítica propia de las "sociedades disciplinarias") (Foucault, 1994 y 2012) a una novela en la que el hospital trasciende sus propios muros y abarca el conjunto del territorio y aún de la vida (es decir, en tanto que el "encierro" se produce ahora, en este texto, "al aire libre", tal y como señalaba Deleuze (1999) cuando caracterizaba a las "sociedades de control") nos alerta acerca de las formas en las que el biopoder muta, en las últimas décadas del siglo XX, para no perder su eficacia.

Nótese, en este sentido, que un autor como Agamben (que recoge los estudios de Foucault $y$, en cierta medida, críticamente, la lectura que de este hacía Deleuze) había propuesto que tomáramos el campo de exterminio como el "paradigma" secreto de la biopolítica occidental actual $(2003)^{2}$. De este modo, viviríamos todavía, según este autor, en un "estado de excepción" permanente, a imagen y semejanza de la vida en el Tercer Reich. Sin embargo, en Impuesto a la carne, se recurre al motivo del hospital y no, por ejemplo, a la figura del campo para narrar los modos en que los cuerpos y las vidas de los personajes están siendo capturados por la lógica biopolítica. La pregunta es: ¿por qué se apela a esta imagen? ¿Por qué su centralidad en un texto publicado a comienzos de los 2000? Creemos que de la novela de Eltit se desprende que ya no es el campo sino el hospital lo que se erige como el eje, más o menos oculto, del funcionamiento actual de biopoder ("el mundo y su dirección, los hospitales") (Eltit, 2010: 122). Si viviéramos aún, como sugiere Agamben, en un "estado de excepción", parece ser que este sería, en todo caso, un "estado de excepción médico". O, como propone Esposito (2005), un "estado de excepción" de tipo "terapéutico" o "inmunitario".

\footnotetext{
2 "El campo como localización dislocante es la matriz oculta de la política en que todavía vivimos, la matriz que tenemos que aprender a reconocer a través de todas sus metamorfosis, tanto en las zones d'attente de nuestros aeropuertos como en ciertas periferias de nuestras ciudades" (Agamben, 2003: 223-224).
} 


\section{LA IMAGINACIÓN POLÍTICA DE LA INMUNIDAD (I): EL CUERPO}

Para seguir los hilos que entendemos que la novela nos lanza (desde el ejercicio del poder soberano a las prácticas biopolíticas, de las "sociedades disciplinarias" a las "sociedades de control", de las "sociedades de control" a la deriva de las "sociedades terapéuticas"), creemos que puede ser conveniente, por tanto, tener en cuenta las propuestas filosóficas más recientes en torno a la noción de biopolítica. En particular, nos parecen especialmente pertinentes los planteamientos de López Petit (2009) y, sobre todo, de Esposito (2005 y 2009) alrededor de la idea de un "poder terapéutico" y de la categoría de "inmunidad".

Estas propuestas vendrían a articular de forma más compleja las distintas declinaciones que este concepto, el concepto de biopolítica, acepta desde que Foucault lo reformulara en la década de los 70. Tanto la idea del "poder terapéutico" como la categoría de "inmunidad" superan la oposición que se reproduce continuamente entre las acepciones más divulgadas del concepto de biopolítica, de las que podríamos considerar autores paradigmáticos a Negri (que toma el relevo de Deleuze en relación con las biopolíticas "positivas", aquellas que hacen referencia a las prácticas que se centran en la reproducción y la administración de la vida) (Hardt y Negri, 2002; Deleuze, 1999) y a Agamben (que insiste en la vertiente "negativa", esto es, en la capacidad de "arrojar a la muerte" de las biopolíticas contemporáneas, de modo que podríamos calificarlas también, según este autor, como prácticas "tanatopolíticas") (2003). La categoría de "inmunidad" vendría a ser, de hecho, según Esposito, el "nodo teórico" habilitado en medio de los dos polos anteriores, en tanto que alude a una "forma de protección negativa" de la vida (2009: 19-20).

Según el autor de Immunitas, en efecto, es precisamente un exceso de protección (la acepción positiva de la biopolítica) lo que, en la actualidad, impide el desarrollo de la vida y lo que la acaba suprimiendo (asociándose ya con la acepción negativa); un exceso de protección, en cualquier caso, que (en la línea de las transformaciones del poder que describía Deleuze (1999) en su "Post-scriptum") no alude tanto a una "forma de sujeción violenta que el poder ejercita... sobre la vida" (2009: 20-21) como al "modo contradictorio en el que la vida intenta defenderse, cerrándose a aquello que la circunda" (ibídem). Efectivamente, cuando la vida se cierra a "aquello que la circunda", no solo está llevando a cabo una acción defensiva o de "protección" (no solo está tratando de asegurar su conservación gracias a ella), sino que mediante esta acción inmunitaria puede estar al mismo tiempo, "bloqueando" su desarrollo y estar colocándose así, en última instancia, en "riesgo de implosión" (de "autonegación") (ibídem). Creemos que la novela de Eltit, Impuesto a la carne, pone en imagen (Link, 2009) las dinámicas inmunitarias del biopoder actual y nos permite aprehenderlas. La imagen de un mundo convertido en hospital podría constituir — tal es nuestra primera 
hipótesis - el eje de la imaginación política de nuestro presente, lo que podríamos denominar la "imaginación política de la inmunidad".

Después de leer los textos de Eltit, no puede sorprendernos en todo caso que Esposito considere que resulta evidente que "la política entra en pleno derecho en el paradigma inmunitario cuando toma la vida como contenido directo" (2005: 160) de su actividad. Lo que este autor sugiere, y lo que los relatos que manejamos vendrían a imaginar, es que lo que ocurre no es solo que la política se alce como biopolítica al tomar la vida como el objeto de su ejercicio; según Esposito, cuando esto sucede, la biopolítica empieza a configurarse como un ejercicio progresivo y reiterado de inmunización: "Ya se trate de la vida del individuo o de la vida de la especie, la política ha de poner a salvo a la vida misma, inmunizándola de los riesgos que la amenazan" (ibídem). Este parece de facto el argumento que funciona de base en el relato de Eltit, el argumento que obliga a que el territorio que habitan los personajes se administre como si fuera un hospital y el que hace que estos, la madre y la hija, sean conducidas a un "estado de alerta" permanente:

"Estamos en permanente estado de alerta porque nuestras vidas se deslizan a través de una línea multitudinaria de cuerpos, una larga geografía colmada de pacientes sumisos. Una ostentosa fila de pacientes severos o terminales que conforman el entorno de lo que ha sido nuestra difícil existencia.

Un mundo enfermo.

Una realidad horizontal que nos amenaza" (Eltit, 2010: 12) ${ }^{3}$.

Lo que nos permite entender Impuesto a la carne, además, es el significado concreto que adquiere la idea de inmunidad en tanto que acto de "poner a salvo a la vida". En esta cita, podemos observar que el primer desplazamiento que implica la biopolítica es la reconducción de su actividad al "régimen del cuerpo". Lo que en principio, por tanto, se nos presentaba como una relación entre dos términos, la política y la vida, se

\footnotetext{
${ }^{3}$ De forma complementaria a la tesis de Esposito - la tesis de que "la política entra en pleno derecho en el paradigma inmunitario cuando toma la vida como contenido directo" - Canguilhem nos insta a considerar en todo caso, también, el proceso inverso, según el cual el "descubrimiento" de la inmunidad en el ámbito médico repercute en el desarrollo de las medidas biopolíticas a partir, ya, del siglo XIX: “EI descubrimiento, debido a Koch, Pasteur y sus alumnos, de los fenómenos de contagio microbiano o viral y de la inmunidad, la invención de las técnicas de antisepsia, sueroterapia y vacunación proporcionaron instrumentos de eficacia masiva a las exigencias de la higiene pública. Paradójicamente, el éxito de los primeros métodos curativos basados en la microbiología provocó en el pensamiento médico la sustitución progresiva del ideal personal de curación de los enfermos por un ideal social de prevención de las enfermedades (...). La imagen del médico hábil y atento de quien los enfermos singulares esperan su curación va siendo ocultada, poco a poco, por la de un agente ejecutor de las consignas de un aparato de Estado encargado de velar por (...) la salud de 'todo ciudadano'" (2004: 78-79). Más abajo retomaremos este proceso de retroalimentación entre la inmunología y la biopolítica.
} 
revela de inmediato como una tríada, en la que debemos incluir el cuerpo; este aparece como el elemento que "representa" el curso de la vida y que lo "vincula" a la realidad ("nuestras vidas se deslizan a través de una línea multitudinaria de cuerpos, una larga geografía..."). El cuerpo constituye, antes que nada, el espacio en el que la vida se despliega y a partir del cual la vida puede desarrollarse (incentivarse, multiplicarse, etc.) y reproducirse (Foucault, 2012: 133). Son los límites del cuerpo los que marcan asimismo los límites dentro de los cuales la vida transcurre. Ahora bien, en tanto que el cuerpo es delimitado como el lugar en el que la vida se despliega, también es inevitablemente, en un argumento "perfectamente reversible", el lugar sobre el que recae todo aquello que la amenaza (un "mundo enfermo"). Es, por ende, el cuerpo, el que debe ser atendido y lo que hay que "proteger". Por esto es el contenido directo, el objeto privilegiado de la biopolítica.

Esto explica, al menos en parte, que la metáfora tal vez más popular, entre todos los tropos que podrían representar la vida de la sociedad, haya sido justamente la metáfora del cuerpo. A partir del siglo XVII, la historia de Occidente, desde los ensayos y tratados políticos hasta los textos literarios y/o de ficción, está atravesada por imágenes del cuerpo que hacen referencia a la formación, constitución u organización de una determinada sociedad (de un determinado "organismo" social o político). En este artículo, por cuestiones de espacio, no podemos asumir la tarea de realizar un estudio ni siquiera mínimamente exhaustivo sobre el recorrido histórico de dicha metáfora. Sin embargo, sí creemos que puede ser oportuno tener en cuenta la idea fundamental que se desprende de dicho recorrido. En él, observamos que la vida de la sociedad o del Estado, el "cuerpo social", debe ser, siempre, protegido de los enemigos y las amenazas que lo acechan. Tanto unos como otras son además, comprendidas como elementos ajenos al cuerpo social, aunque ya se encuentren en el interior de este. El uso de la terminología médica es, en este punto, muy elocuente: los enemigos son tratados como enfermedades, que hay que bien erradicar o extirpar del cuerpo de la sociedad, o bien impedir que consigan introducirse en él, contagiarlo. Lo que se debe hacer, entonces, nos dice la sucesión de metáforas orgánicas, es proteger los límites de la identidad de la sociedad, del cuerpo social que, en cada caso, se ve amenazado. "La caracterización inmunitaria que la metáfora del cuerpo" adquiere entre los siglos XVII y XIX, y que le es conferida, como señala Esposito, "a la totalidad del léxico político moderno" no es, en absoluto, al menos desde el punto de vista de este artículo, irrelevante (2005: 162). Porque, como señala Esposito, "si la metáfora organológica está en el centro de la tratadística política, la enfermedad está en el centro de la metáfora": "es cierto que el punto de cruce entre saber político y saber médico está constituido por el problema en común de la conservación del cuerpo. Pero es desde la perspectiva abierta por la enfermedad que esta conservación 
adquiere una importancia central" (ibídem: 172). Por ello, en fin, como escribe Neuman, "el hospital te convierte en un cuerpo" (2012: 107).

\section{LA IMAGINACIÓN POLÍTICA DE LA INMUNIDAD: EL SISTEMA INMUNOLÓGICO}

El El lugar que la política asigna al cuerpo de cada individuo y la función que el cuerpo cumple en la imaginación sobre lo viviente nos permite entender el papel central que juega la biomedicina en la articulación de la práctica política y, en general, en las sociedades occidentales a partir de mediados del XVIII. Si el cuerpo se convierte en el espacio en el que la práctica política adquiere su último sentido, es lógico que la cuestión de la salud se convierta en el eje sobre el que va a girar, a partir de ese momento, el grueso de la actividad "económica, administrativa y política" del Estado (Foucault, 1999a: 366). En este contexto, comienza el proceso de expansión de la institución sanitaria, que empieza a ocupar franjas cada vez más amplias de la vida social, y que Foucault define, de hecho, como una "estrategia biopolítica" (ibídem) ${ }^{4}$. Los textos de Eltit han sabido capturar en imágenes tanto los mecanismos a través de los cuales se organiza este proceso de medicalización de la vida (las estrategias de control de las epidemias, por ejemplo, en una "patria médica plagada de controles parciales o totales") como los efectos que este produce en el presente sobre nuestros cuerpos (a través de "un cuerpo [médico] que se abocaría a tratarnos con una cantidad alarmante de medicamentos hasta construir en torno a nosotras un campo magnético") (Eltit, 2010: 15 y 29).

Siguiendo a Esposito, podemos afirmar que el "cuadro inmunitario" en el que se inscribe este "proceso general de superposición entre práctica terapéutica y ordenamiento político [es, incluso] demasiado obvio" (2005: 199). Como ocurría en las primeras sociedades biopolíticas, la vida, hoy, en tanto que objeto de atención política, debe ser "inmunizada" preventivamente contra todo aquello que la amenaza. La novedad que se desprende, en cualquier caso, de los imaginarios que conjugan los textos de Eltit con respecto a las imágenes, más bien rudimentarias, que podemos encontrar en los tratados políticos del XVIII y del XIX, es, fundamentalmente, que el ejercicio político de inmunización de nuestras sociedades pasa por llevar al extremo el

\footnotetext{
${ }^{4}$ En el "Nacimiento de la medicina social", Foucault escribe: "El control de la sociedad sobre los individuos no se operó simplemente a través de la conciencia o de la ideología, sino que se ejerció en el cuerpo, y con el cuerpo. Para la sociedad capitalista lo más importante era lo biopolítico, lo somático, lo corporal. El cuerpo es una realidad biopolítica; la medicina es una estrategia biopolítica" (Foucault, 1999a: 366). Para el estudio de los procesos de medicalización en Europa entre los siglos XVIII y XX pueden consultarse, entre otras, las siguientes fuentes: Foucault, 1999a, 1999b y 1999c; Illich, 1975, 1993 y 1996; y, Comelles y Martínez, 1993.
} 
principio de individualización que comienza entonces ${ }^{5}$. "La vida" ahora, como escribe Esposito, "debe ser separada y encerrada en espacios de progresiva desocialización que la inmunicen de toda deriva comunitaria" (ibídem: 199) -esa "línea multitudinaria de cuerpos" entre los que se desliza "horizontalmente" nuestra vida, como veíamos al inicio con Eltit (2010: 12)-.

La pregunta entonces, en este punto, es: si los textos políticos del XVIII-XIX generaban las metáforas del "cuerpo social" a partir del saber y la imaginación médica que les eran contemporáneas (desde las imágenes sobre la degeneración hasta la teoría celular), ¿qué saberes o figuras nos ofrece hoy la biomedicina en consonancia con esta idea -la idea de la individualización-? ¿Qué prácticas e imágenes médicas se entrelazan y retroalimentan, en la actualidad, con las prácticas políticas, caracterizadas eminentemente por su capacidad de separación e individuación? ¿Qué imágenes del "cuerpo político" generan nuestras sociedades? ¿Cómo se actualiza, si es que se actualiza de algún modo, la metáfora del "cuerpo social"? ¿Cuál es la clave de la imaginación política de nuestra época, en tanto que imaginación que se encuentra en la base de las prácticas biopolíticas contemporáneas? Creemos que Impuesto a la carne, como decíamos al principio, puede ayudarnos a contestar este conjunto de interrogantes. Aunque es cierto que la novela no ofrece una respuesta clara o directa (la imagen del "Mundo Hospital" nos permite llegar hasta ellos y enunciarlos, pero más allá de este cuadro no hallamos una referencia explícita a imágenes o prácticas de la medicina contemporánea que nos permitan responderlos de forma inmediata), creemos, no obstante, que sí aporta pistas suficientes como para que nosotros podamos aventurar una respuesta.

En el texto, como hemos visto, los personajes principales, la madre y la hija, oscilan entre una actitud de rechazo o resistencia frente a las prácticas del cuerpo médico y un deseo de que sus vidas se normalicen "en medio del confinamiento radical", del "teatro médico", en el que habitan $-y$ de acuerdo por lo demás, en esta segunda opción, con los deseos del grueso de los personajes que aparecen en la novela, completamente "entregados a los medicamentos"- (Eltit, 2010: 17 y 184). No obstante, en la última parte del relato, parece que la posibilidad de que la madre y la hija efectúen una desobediencia activa ante el poder terapéutico que las somete puede materializarse, y se refieren incluso a la opción de "dar curso a una rebelión perfectamente organizada" (ibídem: 183). Pues bien, es en este punto, en el que los personajes aluden a las formas de resistencia y/o insurrección que podrían llevar a cabo, donde encontramos, por contraste (en el negativo, digamos, de la imagen del

\footnotetext{
${ }^{5}$ De acuerdo, por lo demás, con la evolución que va de las sociedades liberales dieciochescas a las sociedades neo-liberales de comienzos del siglo XXI, que Foucault describe en el Nacimiento de la biopolítica (2008).
} 
"Mundo Hospital"), una respuesta plausible a las preguntas que hemos planteado y, por tanto, también la clave de la imaginación política de nuestra época. En tanto que el cuerpo es el eje a través del cual se organiza la actividad política, jurídica y económica de ese territorio y el eje sobre el que se efectúa el principio de individuación radical que la sostiene, es a través del cuerpo, inevitablemente, desde donde se debe resistir y transformar dicha actividad. En este sentido es particularmente revelador el tipo de condiciones o prácticas corporales, en tanto que condiciones o prácticas políticas, que tienen en cuenta la madre y la hija, porque todas ellas apuntan al objetivo de restablecer, precisamente, el horizonte comunitario (los otros cuerpos) del que se les ha separado e inmunizado: "sí, podríamos empezar la comuna del cuerpo" (ibídem: 184). En el último apartado de este artículo tendremos que volver sobre este motivo, pero de momento es suficiente con que mencionemos las prácticas y las condiciones de constitución de esta comuna. Así, cuando la madre se pregunta cómo podría llegar esta a constituirse, la hija alude, primero, a un concepto de enfermedad que se oponga a la idea de salud que recorre la novela (esa "salud dominante") (Deleuze, 1996: 14); y, después, a una serie de elementos que cuestionan los límites del cuerpo, aquellos que, a priori, marcan también los límites del individuo, su adentro y su afuera, lo propio y lo impropio, y, en consecuencia, también los límites de la salud y de la enfermedad: "No sé, tenemos que pensar, que pensar, que seguir pensando. ¿Continuar pensando qué?, me pregunta mi madre. Los orificios del cuerpo"; "No dejes de considerar la piel, la piel, ¿me entiendes?" (Eltit, 2010: 133 y 142). Las condiciones y las prácticas por las que pasa la materialización de la "comuna del cuerpo" nos permiten, en efecto, y nos obligan, a replantear las preguntas que formulábamos más arriba. Para ser más precisos, tal vez, deberíamos preguntarnos cuáles son las figuras o imágenes médicas que trabajan sobre los límites del cuerpo y de la identidad individual (sobre lo interno y lo externo, sobre lo propio y lo ajeno, etc.) y cuál es, además, la especialidad o la disciplina de la biomedicina que cuida de ellos, de dichos límites, para que el cuerpo no enferme, dado que será aquí y de aquí, probablemente, de donde estas imágenes, en la actualidad, broten. Las respuestas a estas cuestiones no se hacen esperar y no podían ser otras: la figura, la imagen; el sistema inmunológico; el saber, la disciplina; la inmunología:

"Los discursos científicos (...) contienen y ponen en escena de manera condensada las luchas por los significados y las prácticas. El objeto principal de mi atención -escribe Haraway- será el potente y polimorfo objeto de fe, de conocimiento y de práctica llamado sistema inmunitario. $\mathrm{Mi}$ tesis consiste en que éste es un icono elaborado para importantes sistemas de 'diferencia' simbólica y material en el capitalismo tardío. Como objeto del siglo XX, el sistema inmunitario es un mapa diseñado para servir de guía en el reconocimiento y en la confusión del yo y del otro en la dialéctica de la biopolítica occidental, es decir, es un plan de acción 
para construir y mantener las fronteras de lo que se entiende por 'el yo' y por 'el otro' en el importante terreno de lo normal y de lo patológico" (Haraway, 1995: 349-350).

Desde aquí, efectivamente, desde el entorno de este "potente y polimorfo objeto" (ibídem: 349) que constituye el sistema inmunológico, se actualizan y se perfeccionan las imágenes del cuerpo, del individuo y del cuerpo social que están en la base de nuestras sociedades, en la línea que dibuja la biopolítica occidental en los últimos siglos. El poder, hoy y "cada vez más", gobierna la vida a través del "gran aparato de figuras" que la ciencia médica y su punta de lanza, la ciencia inmunológica ${ }^{6}$, elaboran en torno a la "necesidad de autoprotección del cuerpo" (ibídem: 349-351). A continuación, entonces, vamos a revisar brevemente el proceso de construcción de esas figuras y sus connotaciones políticas. Luego, en el último punto, trataremos de pensar, como nos pide la hija en Impuesto en la carne, de qué maneras podríamos socavarlas y sobre qué otras imágenes y prácticas podríamos desplegar nuestras formas de vida.

Para la primera tarea, debemos partir irremediablemente de la idea de inmunidad que se impone como concepto hegemónico tanto en el interior de la comunidad científica como en el ámbito social y el sentido común. Aunque la inmunidad, en tanto que objeto de estudio de la inmunología, haya sido objeto de constantes redefiniciones a lo largo de su no tan extensa historia (en una serie que de hecho todavía prosigue), la representación que en efecto prevalece sobre ella es la que la entiende como la "defensa del organismo contra los elementos extraños que amenazan su integridad" ("fisiológica y funcional”) (Esposito, 2005: 216). Es sobre esta concepción básica sobre la que se van a proyectar los últimos estereotipos del cuerpo y la identidad individual de nuestras sociedades. Una concepción que se torna especialmente efectiva (y a la vez particularmente problemática) después de la traducción de esta función de defensa en términos militares, en un hecho de discurso crucial en el que participan no solo las instancias de divulgación o los media, sino también los propios investigadores biomédicos a través de textos, supuestamente, científicos" " "El sistema inmunitario se

\footnotetext{
${ }^{6}$ Como señala Haraway, "el campo de la inmunología es en sí mismo una industria de crecimiento internacional" que estará en un futuro cada vez más próximo "en el centro de la desigualdad biotecnológica global y de las luchas por las 'transferencias de tecnología"”. Según la autora estadounidense, "su importancia se acerca - efectivamente- a la de la tecnología de la información en las ciencias políticas globales" (1995: 350-351).

${ }^{7}$ Esta circunstancia hace que Esposito se pregunte si "se trata de ensayos de medicina relatados a través de imágenes militares o de libros de estrategia militar ilustrados con metáforas médicas" (2005: 221). Treichler se refería también en este sentido, y en relación con el caso del sida, a una "epidemia de significación", en el que unos discursos se contagian de otros: "Sin embargo, la epidemia de SIDA -con su genuino potencial de devastación global- es, simultáneamente, la epidemia de una enfermedad letal transmisible y una epidemia de significados o de significación" (1987: 263-264).
} 
describe allí como un verdadero dispositivo militar defensivo y ofensivo contra todo lo que no es reconocible como 'propio' y que por tanto debe ser rechazado y destruido"; "una auténtica guerra, cuya prenda en disputa es el control, y en última instancia la supervivencia, del cuerpo", ante un conjunto ilimitado de "invasores externos" (ibídem: 217).

Los ejemplos de este proceso de construcción de significado son múltiples en todos los ámbitos citados. Esposito, no obstante, se demora especialmente en un texto especializado de Lennart Nilsson, en el que se desarrolla con detalle la metáfora de la guerra inmunitaria que se estaría librando en nuestros cuerpos. Este texto, The Body Victorious. The Illustrated Story or our Immune System and Other Defenses of the Human Body (1985), traza un relato en el que se suceden la "detección del enemigo", la "activación de las líneas de defensa", el "lanzamiento de la contraofensiva", la "eliminación física de los adversarios" e, incluso, la retirada de las "víctimas" del "campo de batalla" (Esposito, 2005: 221-225). Las "fuerzas" del sistema inmunitario que llevan a cabo esta cadena de acciones son definidas como "regimientos de reclutamiento y desmovilización rápidos", "tropas de asalto", "francotiradores" o, incluso, como un "pelotón de ejecución" (ibídem). El arsenal con el que cuentan incluye "tanques blindados", "minas químicas" o "dinamita biológica" (ibídem). En este relato, finalmente, el procedimiento inmunitario pone a salvo el cuerpo y la integridad del individuo y acaba con cualquier tipo de amenaza que provenga del exterior del organismo. Además, una vez que este ha sido inmunizado, se supone que "el enemigo no podrá atacarlo más" (ibídem: 225). La idea del cuerpo y del cuerpo social que recorre las páginas de los tratados políticos entre el siglo XVII y el siglo XIX retornan de este modo en este surtido de metáforas inmunitarias, y son actualizadas y reforzadas por el discurso biomédico más sofisticado. Como escribe Esposito, "impresiona" el modo en que "se subordina una función biológica a una visión general de la realidad", "dominada por la exigencia violentamente defensiva con respeto a todo aquello que resulte extraño" (ibídem: 29). El individuo, así, en una sociedad inmunizada, en un "Mundo Hospital", puede seguir desarrollando su vida individual, en ocasiones cerca pero nunca atravesado o contagiado por lo otro o los otros cuerpos. El autor de Immnunitas, sin embargo, se pregunta: "pero, ¿en verdad se dan las cosas de este modo? ¿Puede acaso la victoria del cuerpo sobre sus enemigos ser tan plena y definitiva?" (ibídem: 225). Parece, efectivamente, que no. En las representaciones hegemónicas de la dinámica inmunitaria se impone todavía un "rasgo mítico" que, según Esposito, "termina ocultando los elementos problemáticos y contrafácticos" que estas implican. En relación con la idea del individuo y del "sí mismo" o del "yo", que queda configurado como hemos visto como una "entidad (...) protegida por rígidos límites genéticos y casi identificado con la lucha por defenderlo"; en cuanto a la 
supuesta infalibilidad, también, del sistema inmunitario en su vertiente bélica ("Este es todo - afirma el filósofo italiano- menos un dispositivo perfecto"); y, sobre todo, en relación con las consecuencias que produce, en la vida que se somete a defensa, un exceso de inmunidad (ibídem: 200-201 y 225-226). Hacia las imágenes y los "fantasmas" (Link, 2009) que configuran el imaginario político actual de la inmunidad, apunta en todo caso la imaginación que ponen en juego la madre y la hija en la última parte de Impuesto a la carne.

\section{Hacia la "INMUNidAd COMÚn": LA "COMUnA del CUeRPo"}

Más arriba, cuando introducíamos la categoría de "inmunidad" a partir de la obra de Esposito, observábamos que esta remitía a una forma de "protección negativa" de la vida; "protección negativa" porque, en ese afán de protección, separaba la vida de todo aquello que la rodeaba e impedía de este modo su desarrollo, hasta tal punto que provocaba un efecto de "implosión" o "auto-negación" sobre la vida misma (2005 y 2009). Pues bien, esta descripción del procedimiento (biopolítico) inmunitario no solo incluye y tiene en cuenta el papel que juega en él, en dicho procedimiento, la biomedicina, sino que además coincide, punto por punto, con la crítica que Esposito vierte sobre la historia "oficial" de la disciplina médica de la inmunología: en este sentido "negativo", justamente, se refiere a los "elementos problemáticos y contrafácticos" que pueden contener las dinámicas inmunitarias.

En los textos de Eltit, no cuesta distinguir los principales efectos nocivos de los procesos de medicalización e inmunización de la vida que habita en un "Mundo Hospital". Desde las primeras páginas, encontramos en la novela múltiples escenas en las que, efectivamente, el poder médico se excede en sus funciones o en sus procedimientos y provoca daños clínicos irreparables sobre la vida de los sujetos. Sin embargo, quizás lo que más llama la atención no son los errores o los daños clínicos que generan los procesos de medicalización excesiva. Resulta más sorprendente y más "problemático" constatar que, en otros pasajes, cuando el poder médico actúa como se espera, cuando alcanza los objetivos que se propone a través de los medios a priori oportunos, protocolarizados (esto es, sin excederse), produce igualmente efectos negativos sobre la vida de los personajes. Esta circunstancia, recogida en la novela, ya había sido objeto de preocupación, en cualquier caso, para Foucault. En un texto de 1976, "Crisis de la medicina o crisis de la antimedicina", Foucault afirma, en esta línea, que la "facultad" de hecho de "matar" de la medicina ${ }^{8}$ no está asociada únicamente a los defectos que se cometen en su práctica, sino que, más bien al contrario, dicha

\footnotetext{
8 "La medicina mata, siempre mató y de ello siempre se ha tenido conciencia" (Foucault, 1999b: 348). 
capacidad está directamente vinculada a su competencia, "en la medida en que la medicina es una ciencia" (1999b: 347-348):

\begin{abstract}
"Es lo que podría denominarse no ya la iatrogenia", sino la iatrogenia positiva, es decir, los efectos nocivos de los medicamentos que no se deben a errores de diagnóstico ni a la ingestión accidental de una sustancia, sino a la propia acción de la intervención médica en lo que ésta tiene de fundamento racional. En la actualidad los instrumentos de que disponen los médicos y la medicina en general, precisamente por su eficacia, provocan ciertos efectos, algunos puramente nocivos, y otros fuera de control, que obligan a la especie humana a entrar en una historia arriesgada, en un campo de probabilidades y riesgos cuya magnitud no puede medirse con precisión" (ibídem: 349).
\end{abstract}

Como señala Esposito, las formas que han adoptado dichos efectos a lo largo de la historia son numerosos. Si seguimos la lectura de Impuesto a la carne, podemos distinguir algunos de ellas, como la individualización de las enfermedades, que impide que consideremos y actuemos sobre sus condiciones sociales, o el bloqueo de nuestra capacidad de auto-asistencia (Illich, 1975), en tanto que la práctica médica ocupa un lugar y se presenta ante los "ciudadanos médicos" como la única solución razonable y por lo tanto posible a cualquier estado de enfermedad o malestar ${ }^{10}$ (Eltit, 2010: 87 y 93; 2010: 24, 37, 131 y 132). No obstante, adonde queremos llegar es al hecho de que los "éxitos" de la medicalización de la vida resultan "contrafácticos", sobre todo, porque pueden afectar negativamente a las propias capacidades inmunitarias del cuerpo, a la hora de articular las medidas de protección adecuada (esto es, ni excesivas ni deficitarias) ante un riesgo real. Así se sugiere en la novela y así lo afirman de facto Foucault (1999b) y Esposito (2005). Los ejemplos de esta contradicción (tanto los que encontramos en el texto de Eltit como también los que nos ofrece la evolución de la medicina) y las modalidades en las que estos se materializan son igualmente diversas. Una de las "principales", como señala Esposito, "se refiere al mismo tratamiento

\footnotetext{
${ }^{9}$ Aquí Foucault dialoga con las tesis que expone Ivan Illich en Némesis médica. "En el sentido más estricto, -leemos en este texto- la enfermedad yatrogénica (Yatrogénesis, el nombre de esta nueva plaga, viene de iatros, el término griego para "médico", y de genesis, que significa "origen") incluye sólo las enfermedades que no se habrían producido si no se hubiesen aplicado tratamientos ortodoxos y profesionalmente recomendados. En un sentido más general y más ampliamente aceptado, la enfermedad yatrogénica clínica comprende todos los estados clínicos en los cuales los remedios, los médicos o los hospitales son los agentes patógenos o "enfermantes". Daré a esta plétora de efectos secundarios terapéuticos el nombre de yatrogénesis clínica" (1975: 38).

${ }^{10} \mathrm{Y}$ en tanto que este lugar es producto no solo de una evolución neutral de una disciplina dentro de un campo de saber sino también de un proceso histórico de aculturación y destrucción de otras culturas médicas (de poder-saber) que conjugaban de otro modo esta capacidad, la capacidad de autoasistencia; en tanto que el saber biomédico es un saber especializado; en tanto que en cuestiones de salud están en juego la vida y la muerte, etc. (Illich, 1975; Foucault, 1994 y 2007a; y, Comelles y Martínez, 1993).
} 
inmunitario" que ha desarrollado históricamente la medicina con la intención de "defender el organismo" y que sin embargo ha terminado, al menos en parte, por "debilitarlo" (2005: 200), al producir una "disminución general" de su "umbral de sensibilidad" a "los agentes agresores" (ibídem). Es lo que sucedió, de hecho, a partir del "tratamiento" y "la lucha llevada a cabo con el mayor éxito" contra las enfermedades infecciosas de comienzos del siglo pasado. Foucault afirma que debido al "propio efecto de los medicamentos - efectos positivo y terapéutico-, se produjo una perturbación" tanto en el organismo "individual" como en el "ecosistema" de la "propia especie humana": "La cobertura bacilar y vírica, que constituye un riesgo pero al mismo tiempo una protección para el organismo, con la que funcionó hasta entonces", sufrió, en este contexto, una "alteración por la intervención terapéutica" y quedó expuesta desde ese momento a conflictos "contra los que el organismo estaba protegido" 11 (1999b: 348-350). Según Esposito, este tipo de elementos "contrafácticos" responden, en muchas ocasiones, a la misma ecuación, aquella que verifica que "es justamente la protección la que genera el riesgo del que pretende defender": "El riesgo, en suma, requiere protección en una medida idéntica a aquella en que la protección produce riesgo" (2005: 200). La conclusión a la que llega el autor de Immunitas en este punto es especialmente significativa y conviene que la midamos en toda su extensión. Porque si tenemos en cuenta, como advierte el ejemplo de la lucha contra las enfermedades infecciosas, que la medicina y la investigación biomédica trabajan ya no únicamente "en el nivel del individuo" (como podría ocurrir en otros casos durante el siglo XVIII) sino que lo hacen, más bien, como se ha dicho y cada vez más, "sobre la propia vida y sus acontecimientos fundamentales" (Foucault, 1999b: 351), comprendemos que esta ecuación nos informa de un hecho que va más allá del ámbito estricto de la institución médica. En efecto, inmediatamente después, unas líneas más abajo, Esposito reconoce que dicha ecuación describe asimismo el funcionamiento de "todos" los ámbitos de "los sistemas sociales contemporáneos, cada vez más neuróticamente obsesionados por el imperativo de la seguridad" (2005: 200-201)12. Esta "deriva", que Esposito realiza continuamente, entre la "inmunidad" como objeto de estudio de la disciplina inmunológica y la "inmunidad" como categoría biopolítica, es el marco en el que trabaja, ciertamente, Impuesto a la carne.

En este texto encontramos referencias a la "infección" ("como si fuéramos -lamenta la hija - una infección incandescente") e incluso a algunas "interferencias biológicas"

\footnotetext{
11 "Ello significa - continúa Foucault - que en la medida en que el organismo se sabe defender mejor, se protege, naturalmente, pero por otro lado se deja al descubierto y expuesto si se impide el contacto con los estímulos que desarrollan las defensas" (1999b: 158).

12 "Todo el fenómeno de la vida - confirma por su parte Foucault- entra en el campo de acción de la intervención médica (...). Nos encontramos en la biohistoria y esto es algo muy importante" (1999b: 351).
} 
que remiten, parece, a las enfermedades respiratorias que se extendieron a principios del siglo pasado a través del contagio ("interferencias biológicas que me ocasionan sobresaltos en la tráquea (...) y mis bronquios, y que, desde luego, entorpecen la conflictiva cavidad de los pulmones que tengo") (Eltit, 2010: 20 y 32). Pero lo más llamativo, y lo que más se ajusta a la lógica problemática de los tratamientos inmunitarios que revelan Esposito y Foucault, son las alusiones posteriores a "un tipo de debilidad" particular, asociada a un mal funcionamiento de las "defensas" del organismo, parece que causada históricamente ("Experimento un intrincado proceso orgánico detonado por los años y por un tipo de debilidad (...) que me ha acompañado siempre") y sobre la que el poder médico, inmunitario, aún no tiene capacidad o incluso intención de intervenir ("Estamos obligadas a ser las espectadoras de la muerte - prosigue la hija - porque es un ciclo que el territorio, la patria o el país nos endosó. Nos abandonó en este escenario esperando que cedan todas las defensas") (ibídem: 32 y 178). ¿Qué tipo de debilidad podría estar detectando la novela de Eltit? ¿Qué registra la "recurrencia" de las enfermedades de sus protagonistas o la colección de síntomas que acompañan a estas - desajustes en la sensibilidad, "intermitencias nerviosas", "un tipo extrañísimo de alergia y de fatiga", "heridas, manchas o erupciones", etc.? (ibídem: 17, 19 y 40)-.

Aunque en la novela no hay ninguna mención explícita a ellas, a esta altura contamos ya con suficientes argumentos para pensar que lo que quizá acontece a los personajes está relacionado con una disfunción o una enfermedad del sistema inmunológico. 0 mejor: que, más allá de las hipótesis o los diagnósticos que podamos aventurar sobre lo que les sucede a la madre y la hija en el texto, que es aquí hasta donde este apunta. Sabemos, en este sentido, que el funcionamiento de dicho sistema no se ciñe a lo que dicen de él las representaciones hegemónicas y que estás lejos de poder ser considerado un procedimiento infalible o sin contradicciones. Esposito, además, incluye de hecho este tipo de patologías, tanto aquellas que se caracterizan por una "deficiencia inmunitaria" como aquellas llamadas "enfermedades autoinmunes", dentro de este proceso de "inherencia de lo negativo" en el "mecanismo de su control terapéutico" (2005: 226). Las primeras, las enfermedades "inmunodepresoras", se caracterizan, como su nombre indica, por hacer que el sistema inmunitario del organismo no produzca las defensas que este necesita, exponiéndolo por tanto a una serie de infecciones que resulta difícil de soportar, en casi todos los casos, durante un periodo de tiempo largo; las enfermedades autoinmunes expresan por su parte "una contradicción más aguda": "no una disminución, un bloqueo", sino "una falla del aparato inmunitario", que se vuelve contra sí mismo (ibídem: 226-230). Aunque las enfermedades que entran dentro de esta categoría son numerosas ( $y$ de hecho varían según los criterios que se utilizan), todas tienen algo en común: en ellas, un "exceso de 
defensa del organismo", en su intento de suprimir un elemento patógeno, "se daña también a sí mismo" (ibídem: 230). La pregunta que se nos abre entonces en este punto es: ¿podríamos pensar las enfermedades del sistema inmunológico como un efecto o como un síntoma de un medio excesivamente inmunizado, tal y como sería un mundo convertido en hospital (y más allá de otros elementos "contrafácticos" de los dispositivos inmunitarios de seguridad como podría ser el aumento de la violencia sobre ciertos sectores de la población o en relación con el terrorismo)? Sabemos también, de facto, como ha señalado uno de los descubridores del VIH, Robert Gallo, que en el caso del sida (síndrome de inmunodeficiencia adquirida) podría haber ocurrido un proceso semejante al que Foucault describe para las enfermedades infecciosas de principios del siglo $X X$, en relación con los posibles efectos de "facilitación" del desarrollo de la enfermedad por el uso de vacunas y sus consecuencias sobre nuestro sistema inmunitario ${ }^{13}$. ¿Supone este hecho una prueba suficiente? Creemos que la novela nos permite, o nos anima, en cualquier caso, a ir incluso más allá de estas dinámicas que serían, estrictamente, del orden de lo biológico (aunque en sí mismas graves y necesitadas de atención). Si tenemos en cuenta la reivindicación de la hija, a la que nos referíamos al final del apartado anterior, de la enfermedad como un tipo de reacción posible ante un orden social y simbólico dado (un "Mundo Hospital"), la pregunta que nos asalta, con más precisión, es: ¿podríamos pensar las enfermedades del sistema inmunológico como efecto de un trabajo de inmunización social que opera no solo a nivel del organismo, del sistema inmunitario, y a través de tratamientos farmacológicos, sino que se efectúa también por medio de otros componentes materiales, de seguridad, e imaginarios $-y$ que concluyen, en cualquier caso, en procesos de individualización radical一? ¿Podríamos pensar las enfermedades inmunodepresoras y/o autoinmunes, en tanto que procesos fisiológicos, como un efecto o un síntoma de los procedimientos y los resultados de dicha individualización? ¿No se refiere a esto Esposito cuando afirma que el "impulso de autodisolución" que amenaza a las sociedades contemporáneas, y que explica la categoría biopolítica de la inmunidad, "parece encontrar su réplica más que metafórica

13 "El vínculo entre el programa de la OMS [Organización Mundial de la Salud] -el programa de vacunación para la erradicación de la viruela en África-y la epidemia es una hipótesis interesante e importante. No puedo afirmar que ese vínculo, de hecho, haya existido, pero ya llevo unos años diciendo que el uso de vacunas vivas como las que se usaban para la viruela pueden activar una infección latente como la del VIH" (1987). Dos años después, y más allá del caso del sida, Canguilhem reafirma que "está lejos de excluirse la posibilidad de que la práctica generalizada de la vacunación tenga como consecuencia la aparición [de otras enfermedades] (...). Este es tan solo un aspecto más de una intervención de finalidad que, en las sociedades industriales donde la protección sanitaria se encuentra altamente tecnificada, la proliferación y eficacia creciente de los actos médicos y quirúrgicos arriesga multiplicar las fallas en el sistema biológico interno de resistencia a las enfermedades" (2004: 38). 
en esas enfermedades"? (Esposito, 2005: 29) ¿O, acaso los tratamientos médicos, la "precipitación farmacéutica" (Eltit, 2010: 179) y las consecuencias que producen son la única materialización, la única puesta en escena posible, de esa compleja relación que Haraway (1995) señalaba entre la inmunidad como categoría biopolítica, la inmunología como punta de lanza de la investigación biomédica y farmacológica, y las enfermedades del sistema inmunitario - cuya tasa de incidencia crece, exponencialmente, en nuestras sociedades -?

Este conjunto de problemas, en fin, que remite más a un horizonte justamente de pensamiento que a una solución, es el que hace visible, creemos, la novela de Eltit. Vamos a continuar por tanto con su lectura, a partir del punto en el que la habíamos dejado en el apartado anterior, para tratar de acercarnos a esos problemas $y$ comprobar si es factible, entonces, no ya hallar las respuestas ("No estoy aquí -insiste la hija- para revelar secretos o verdades") (Eltit, 2010: 179) pero sí poner en juego, a través de sus imágenes, otra imaginación (política) en la que no prevalezca el exceso de inmunidad, en la que la protección no genera el riesgo del que nos quiere proteger, en la que en definitiva no reine un principio de individuación.

La primera imagen con la que contamos para realizar esta tarea es, efectivamente, la de la enfermedad como "reacción" al medio y como rechazo o negación de esa "adoración por el buen estado general de la salud" que profesa una mayoría social en el texto de Eltit. La madre y la hija oponen "la furia de nuestras enfermedades o la aridez de nuestras enfermedades" al control terapéutico, a la organización médica del "territorio" y a esa idea de "salud dominante" (Deleuze, 1996: 14). Como señalábamos más arriba, en tanto que el poder que pone en escena la novela es un poder que se ejerce a través del cuerpo, por parte de un "cuerpo médico" y a partir de una idea de salud (rigurosamente, un "biopoder"), la única forma que las protagonistas encuentran para articular frente a él una posición crítica es, justamente, poner el cuerpo en "crisis" a través de la enfermedad ("Sostengo - afirma la hija en un momento dado- los detalles de cada una de las crisis") (Eltit, 2010: 39). Gracias a esta y a los diversos síntomas que presentan, los médicos, en todo caso, no pueden someter, normalizar o incluir en los aparatos de producción a la madre y a la hija. La enfermedad se expresa aquí, de hecho, como una manifestación de la vida, un "ímpetu orgánico", que los médicos, en tanto que "funcionarios de los órganos", "no terminan -decíamos- de entender": son "segmentos en constante rebeldía que se fugan y se les escapan"14 (ibídem: 11, 131-132 y 158).

\footnotetext{
${ }^{14}$ La novela dialoga aquí con la noción de enfermedad que maneja Foucault (siguiendo a Canguilhem) en el último artículo que mandó a publicar antes de morir (de sida), titulado "La vida: la experiencia y la ciencia". En este texto, Foucault afirma que "la vida es aquello que es capaz de error" (capaz de 
Nótese, en esta línea, la complejidad que adquiere en el texto la idea de la enfermedad. Por un lado, aparece como una manifestación de la vida que emerge y se manifiesta en el plano físico (en "la irreprimible historia de mi cuerpo", como puntualiza la hija) (Eltit, 2010: 183), pero por otro, también, como una reacción que puede ser incitada por el propio sujeto; es decir, como una manifestación fisiológica que es asimismo una reacción subjetiva. Así, la hija no duda en afirmar lo siguiente: "nosotras incitamos a nuestros órganos hacia una posición anarquista y así conseguimos imprimirles una dirección más radical a nuestros cuerpos" (ibídem: 15). No creemos en todo caso que la intención de Eltit sea aludir a una condición real y reivindicar un concepto de enfermedad que se ajuste a esta imagen. Creemos más bien que es una forma con la que el texto atrapa la posible condición de reacción o de síntoma de nuestras patologías, su condición de fenómeno que podría responder a un determinado funcionamiento (opresivo, medicalizado, inmunitario) de la sociedad.

No en vano, es así como se acercan a la idea de la enfermedad autores como Sloterdijk (2001), Brea (2009) o Araujo (2006) en tres textos publicados en los últimos años. Desde diferentes disciplinas, estos autores aplican al estudio de la depresión, el pánico o el sida una noción de "síntoma" que nos ayuda a captar también toda la potencia de sentido que late en los relatos de Eltit, en tanto que es un síntoma que se refiere a un medio, a una sociedad: un síntoma social. Como señala Araujo, este "síntoma" remite a "aquellas formaciones que irrumpen y ponen al descubierto" una falla o un "punto de imposibilidad radical inherente a un modo de organización social" (ibídem: 191$193)^{15}$. Es lo que sucede, parece, en la novela de Eltit. De estos tres estudios, es no obstante el que firma Brea el más revelador con respecto a la propuesta de este artículo, dado que aplica la noción de síntoma social al caso de una enfermedad del sistema inmunológico - el sida - y que contesta de forma afirmativa a la cadena de interrogantes que formulábamos más arriba. Para el autor de "Sida: el cuerpo inorgánico", esta enfermedad constituye el síntoma específico de nuestra época en tanto que la deficiencia inmunitaria que la caracteriza mantendría una relación directa con el exceso de inmunización que caracteriza por su parte a dicha época. Brea define la "inmunodeficiencia" del siguiente modo: "Incapacidad del sujeto para regenerar sus fuerzas de cohesión interna, para producir mecanismos de autodefensa"; "Incapacidad del sujeto para autoproducirse"; "Incapacidad del sujeto para conservarse en sí";

\footnotetext{
"infringir" sus propias normas) y que la enfermedad es una de sus manifestaciones erráticas más "radicales" (2007b: 55).

15 "La enfermedad es, en toda su envergadura, - dirá por su parte Brea - un hecho social, que antes y más debería ser objeto de las ciencias humanas, sociales o del espíritu - que de la biología o la medicina, o cualesquiera ciencias 'naturales'. La enfermedad, es preciso decirlo, no pertenece al ámbito de éstas (...). Esto significa, mucho más allá de la idea de la enfermedad como metáfora, que toda enfermedad no es otra cosa que una pura y efectiva producción de síntoma” (2009: 59-60).
} 
"Incapacidad del cuerpo, del sujeto, para protegerse, para 'querer' autoconservarse"; "Carencia de argumentos para resistir el impulso disgregador, disolutorio" que el cuerpo "enarbola contra... la cultura" (Brea, 2009: 61-62). Que el síndrome de la inmunodeficiencia adquirida constituya el síntoma social de la época contemporánea significa, entonces, según este autor, que el cuerpo deja de protegerse a sí mismo, deja de proteger su vida, porque de algún modo le es imposible vivir así, porque no acepta o ya no le sirve el lugar en el que le dejan el orden simbólico y la organización social contemporánea, porque ya no acepta o no le sirve la individualización, la inmunización frente a los otros y la hiperprotección frente al medio:

"Es esto lo que el sida sintomatiza radicalmente, la impresencia del otro (...) la rotura de toda socialidad. Y es por esto que su carácter epidemial (...) va más allá de la mera circunstancia de ser extremadamente contagioso y hasta la fecha incurable: es una enfermedad radicalmente colectiva, totalmente colectiva, social: es la enfermedad y crisis misma de la socialidad de todo modelo de constitución de la subjetividad" (ibídem: $62)$.

No es necesario hacer complicados malabarismos para constatar que la enfermedad o las enfermedades de la madre y la hija coinciden, en tanto que síntoma, con la descripción del sida que propone Brea. Esto no significa, en cualquier caso, que los personajes de Impuesto a la carne tengan sida. Lo que queremos decir, insistimos, es que, más allá del diagnóstico (que el texto nunca ofrece), la enfermedad en la novela atrapa y apunta a este horizonte inmunitario. De hecho, para Brea, no solo el sida constituye un "hecho social". "No importa en realidad - llega a escribir-cuál sea la enfermedad": "no hay ningún desorden "axiológicamente neutro", inocente, puramente "del cuerpo", por así decir. Sino que es la escritura que en este imprime un orden de convicciones, una constelación reguladora de la relación del sujeto con el mundo - una biopolítica-, la que es fallida" (2009: 59-60). Cuando la hija afirma, en el texto de Eltit, que "el estado general que describo es propio de cualquier cuerpo y más aún de aquellos invadidos por la enfermedad. Yo prefiero hablar de un cuerpo, el mío, pero desde la mensura del tiempo, integrando la locura de los signos de los tiempos" (2010: 128), está queriendo decir, creemos, lo mismo que Brea. Si su enfermedad o enfermedades, por tanto, consisten en un "debilidad", en un descenso de sus "defensas" o, quién sabe, en una "deficiencia inmunitaria", en tanto que "hechos sociales" aluden a un exceso de "fuerza", de "protección", de "inmunidad" de la sociedad en las que se desencadenan. Si la enfermedad, finalmente, les llevara a la muerte, cosa que no ocurre en la novela, podríamos hablar por tanto, como hacía Esposito, de un proceso de "protección negativa" de la vida que ha llevado a esta a un proceso de “implosión" o "auto-negación" (2005 y 2009). 
¿En qué coinciden, entonces, en qué aspectos concretos, las enfermedades de la hija y de la madre y el sida, si seguimos la descripción que realiza Brea, para que podamos alcanzar dichas conclusiones? Antes que nada, es notorio que ambas "reaccionan" o son "síntoma" de un mundo regido por un principio radical de inmunizaciónindividuación. "La impresencia del otro" a la que se refiere Brea (2009: 62) es lo que la hija verifica y confronta constantemente en Impuesto a la carne, cuando se refiere a ella y a su madre, de forma repetida, como a "mujeres solas", "cercadas por médicos" (Eltit, 2010: 24 y 33), que asisten a la "rotura de toda socialidad" (Brea, 2009: 62). Pero si profundizamos en este aspecto, nos damos cuenta, además, que esta serie de enfermedades cuestionan asimismo la idea de "individuo" que está en la base lógica de dicho principio - de individuación-. Cuando Brea escribe así que no hay "desorden" que pertenezca únicamente al orden del cuerpo y que toda enfermedad está asociada a una "constelación" que "regula" la "relación del sujeto con el mundo" (ibídem: 259-260); y cuando la hija afirma, de algún modo corroborando las tesis de Brea, que puede incitar a su cuerpo hacia la enfermedad, no solo se está marcando la enfermedad como un hecho en relación con lo social. Al mismo tiempo, estas proposiciones impugnan, efectivamente, el concepto moderno de individuo, dividido en un cuerpo y una conciencia, soberano sobre ese cuerpo, etc.; rompen esa "tensión vertical", porque, en el sida, "es el cuerpo sólo, definitivamente, el que piensa -el que existe- en una tensión orgánica": "el espacio de la conciencia" ya no está aislado ni privilegiado en la parte superior del individuo, sino que "resulta poblado exclusivamente por la (...) inscripción sinérgica del cuerpo" (ibídem: 59-63). Por ello, insiste Brea, "el sida no 'representa nada' ni es 'metáfora' de nada (ibídem). Constituye un síntoma en tanto que "efectúa" en el cuerpo una "condición", un "estado del sujeto", de hecho precisamente su "desvanecimiento como fantasmagoría retenida y producida" por el "programa (...) de la metafísica occidental" (ibídem).

Es desde aquí, desde la reivindicación de la enfermedad como "síntoma" o "hecho social" y como reacción por tanto ante una idea de la salud que organiza nuestras vidas de acuerdo a un principio de inmunización e individualización; desde la enfermedad como hecho que pone en crisis la idea del individuo moderno; desde donde tenemos que leer el resto de imágenes del cuerpo que encontramos en Impuesto a la carne: las imágenes de los cuerpos expuestos a partir de la piel y abiertos a través de los orificios corporales. Recordemos que, hacia el final de la novela, la hija insta a la madre a "considerar la piel" ("Esta piel de animales que tenemos o que somos, ¿me entiendes") y a "pensar", a "seguir pensando" en "los orificios del cuerpo" ("mamá, los hoyos que tiene") como medios desde los que resistir o socavar el poder biomédico (Eltit, 2010: 133 y 142). Como señalábamos en el apartado anterior, justamente las zonas del cuerpo que representan o problematizan 
la idea de los límites del individuo y que en consecuencia habría que "proteger" (para inmunizarlo). La estrategia de la hija y de la madre, decíamos, parecía entonces clara: dado que el dispositivo médico ejerce su poder a través de la individualización de los cuerpos y en pos de un objetivo de salud general la única forma de conmoverlo consiste en colocarse en un estado de exposición y/o de apertura (de "desprotección") a lo otro, a los otros cuerpos y así a la enfermedad. Si pensamos en una enfermedad de nuestra época que se corresponda con ese estado nos topamos de frente, de nuevo, con el sida. Este sería el ejemplo paradigmático de una enfermedad que se produce a causa de la vulneración de los límites del individuo (por contagio y a través de la piel o de los orificios del cuerpo) y que, a su vez, los cuestiona, en tanto que derrumba las defensas del organismo, exponiendo aún más al sujeto. Como señala Esposito, lo que se hiere en este caso no es solo un "protocolo sanitario", de inmunización, "sino todo un régimen ontológico": el sida "devasta" la noción de individuo "porque destruye incluso la idea de límite identitario" (2005: 229). "No es casual" ni de menor importancia que su transmisión se produzca justamente en aquellas situaciones en las que el sujeto participa de un "existir común" o en las que "socializa su gozo límite", como ocurre en el caso de la droga compartida (a través de la piel) o en el sexo (a través de los orificios). En esas experiencias, sentencia Brea en la línea de Esposito, la "muerte" del individuo - "en verdad, su nunca constituida existencia" - en efecto se "anticipa", se "comunica", se "realiza" (2009: 64).

De este modo, el ejemplo del sida nos lleva de nuevo a la última imagen del cuerpo que la novela contiene. Solamente desde una inmunidad problematizada y desde el cuestionamiento de la idea del individuo que esta enfermedad encarna podemos comprender efectivamente la imagen de la "mutual" o de la "comuna del cuerpo". Como señalábamos más arriba, las estrategias de contacto a través de la piel o los agujeros del cuerpo respondían, de hecho, al objetivo de constituir dicha comuna. Si retomamos, entonces, desde aquí, el enunciado formulado en el párrafo anterior acerca del sentido de dichas estrategias, podríamos reformularlo en los siguientes términos: en tanto que el "cuerpo médico" ejerce su poder a través de los mecanismos de inmunización del cuerpo, la única forma de hacerlo tambalear es a través de las prácticas de "comunicación", de "puesta en común", claro, del propio cuerpo. A esta pareja, compuesta por la inmunidad y la comunidad, interpela la imagen de la "comuna del cuerpo" 16 .

\footnotetext{
${ }^{16}$ Esposito plantea la relación entre los dos términos de esta pareja a partir de la etimología. Según este autor, la communitas y la immunitas proceden de la voz munus, que indica a una suerte de donación obligatoria. Desde esta perspectiva, lo común sería aquello que comprende el munus, la donación (como indica el prefijo cum-); y lo inmune aquello que lo niega (como indica el prefijo in-) (Esposito, 2005 y 2009).
} 
En la novela, en las primeras páginas en las que se hace referencia a ella, parece que la "comuna" funciona más como un horizonte de emancipación que como una posibilidad real contenida en el presente. La hija es consciente de que "la historia no está preparada", de que no se dan las condiciones que se necesitan, de que el "cuerpo social" parece íntegramente inmunizado (Eltit, 2010: 142). Sin embargo, asegura que "lo van a conseguir": "iniciaremos la huelga de nuestros líquidos y el paro social de nuestras materias" y "viajaremos" a "buscar nuestra comuna" (ibídem: 167 y 183-184). A medida que pasamos las páginas, y antes de que ningún viaje se produzca, advertimos no obstante que la materialización de la comuna no se decide tanto en una perspectiva temporal como en una cierta disposición de los cuerpos. Así, en el último episodio de la novela, la hija constata que "se instaló una comuna -ya- en mí rodeada de órganos que se levantan para protestar por el estado de su historia" (ibídem: 183). Solo hace falta por tanto que otro cuerpo se disponga (se exponga, se abra, inicia la huelga de sus defensas) de la misma manera para que la "mutual" o la "comuna del cuerpo" se haga realidad. En este sentido, los órganos que rodean la comuna "instalada" en el cuerpo de la hija "buscan - simplemente- una señal para manifestar su autonomía y dar curso a una rebelión perfectamente organizada" (ibídem). No parece descabellado asociar, en este punto, la posibilidad comunitaria, de puesta en común de los cuerpos, que la novela recoge con las teorías en torno a la comunidad y al "ser-en-común" que un conjunto de filósofos contemporáneos (desde Blanchot a Tiqqun, pasando por Nancy, Agamben o el propio Esposito) ha elaborado. En todos los casos, "en la comuna - del cuerpo - radica la única posibilidad" (ibídem: 180) de trascender el marco de los "cuerpos sociales" y las "comunidades inmunizadas" (Esposito, 2005: 19).

Esta imagen, la de la "comuna del cuerpo", responde en consecuencia a la última pregunta que plantea Esposito a propósito de una hipotética nueva relación entre lo inmune y lo común: "si lo que está en juego en esta trama (...) es una cuestión no solo biológica, sino también filosófica, ¿es posible imaginar una filosofía de la inmunidad que, sin negar su contradicción intrínseca e incluso profundizando más en ella, invierta su semántica, dirigiéndola en sentido comunitario?" (ibídem: 234). La novela de Eltit, en efecto, nos deja imaginar formas de la inmunidad que no cancelen la vía comunitaria y que no supongan, a su vez, una "implosión" o una "auto-disolución" de la vida. La enfermedad, de hecho, nunca conduce en el texto a la muerte de los personajes, sino que es justamente el estado que permite poner el cuerpo en común, a través de la piel y sus orificios. Podemos pensar, entonces, que aunque se trate de un estado de "debilidad" y de vulnerabilidad, que permite el paso de otros cuerpos, no se trata nunca de un estado de inmunidad cero, que conduciría en efecto a la "autonegación" de la vida, a la muerte. De alguna manera, la enfermedad, en Impuesto a la 
carne, sostiene una forma de la inmunidad que no se opone a lo común pero que sigue manteniendo el cuerpo a salvo de su disolución. De hecho, podríamos pensar que no solo eso, sino que además le enviste de una potencia inédita al permitir que su vida se desarrolle junto a otra vida. Así, creemos, tenemos que entender a la hija cuando afirma, al final, que "vamos a morir" y "vamos a nacer otra vez" (Eltit, 2010: 185). Lo que muere en esta forma de inmunidad es el individuo, las "mujeres solas". Esta es la imagen de la inmunidad que la novela pone en pie: la "comuna del cuerpo".

Una imagen, por cierto, que se asemeja a la descripción del funcionamiento del sistema inmunitario que ofrecen los estudios críticos en inmunología más recientes. Estos estudios, efectivamente, se alejan de las posiciones todavía (insistimos) hegemónicas que conciben el sistema inmunitario como una máquina de guerra que trabaja para defender los límites del individuo. Según estos estudios, la función de dicho sistema consiste en regular, en término nunca bélicos, las interactuaciones del cuerpo con los "otros (humanos o no, internos o externos)" (Haraway, apud Esposito, 2005: 235). Esto significa que el cuerpo no estaría entonces al servicio de un ejercicio de protección de los límites del individuo o de su identidad. "Desde esta perspectiva, lejos de constituir una unidad cerrada dentro de límites bloqueados e insuperables, es considerado un ecosistema" permeable que "evolucionó con el paso del tiempo" (ibídem: 236), dentro de un entorno que Tauber definió, justamente, como "comunidad social" (1994). En el centro de esta dinámica de regulación, de interactuación o incluso de contagio con el medio, con lo otro, se encuentra la función de lo que los inmunólogos denominan "tolerancia inmunitaria": una "depresión específica de la respuesta inmunitaria" que se inscribe sin embargo dentro del mecanismo inmunitario y que por lo tanto nunca debe confundirse con una "noinmunidad" (Esposito, 2005: 236-238). Se trata, al contrario, de la capacidad del sistema inmunitario para incluir lo otro dentro del cuerpo, en un proceso de conocimiento y reconocimiento más complejo que el que prevé la idea del enfrentamiento militar y que, finalmente, "derrumba toda distinción presupuesta entre sí mismo y no sí mismo, propio y no propio, adentro y afuera" (ibídem: 239). ¿No parece, ciertamente, que es esta "suerte de inmunodeficiencia virtuosa" (ibídem: 238) lo que pone en imagen la enfermedad de la hija y de la madre en Impuesto a la carne? ¿No es este horizonte de "inmunidad común" (ibídem: 234) al que apela la "comuna del cuerpo"?

\section{BiBLIOGRAFÍA}

Agamben, G. (1999). Homo sacer. El poder soberano y la nuda vida I. Valencia: PreTextos. 
Araujo, K. (2006). Depresión: síntoma y lazo social. En W. Bongers y T. Olbrich (Eds.), Literatura, cultura, enfermedad (pp. 191-211). Buenos Aires: Paidós.

Brea, J. L. (2009). Sida: el cuerpo inorgánico. En Un ruido secreto. El arte en la era póstuma de la cultura. Copia de autor para descarga libre disponible en: http://joseluisbrea.net/ediciones cc/urs.pdf.

Canguilhem, G. (2004). Escritos sobre la medicina. Buenos Aires: Amorrortu.

Comelles, J. M.a , y Martínez, Á. (1993). Enfermedad, cultura y sociedad. Madrid: Eudema.

Deleuze, G. (1996). Crítica y clínica. Barcelona: Anagrama.

Deleuze, G. (1999). Post-scriptum sobre las sociedades de control. En Conversaciones (traducción de José Luis Pardo). Valencia: Pre-Textos. Disponible en: http://www.oei.org.ar/edumedia/pdfs/T10 Docu1 Conversaciones Deleuze .pdf.

Eltit, D. (2009). Colonizadas. En J. Guerrero y N. Bouzaglo (Eds.), Excesos del cuerpo. Ficciones de contagio y enfermedad en América Latina (pp. 79-94). Buenos Aires: Eterna Cadencia.

Eltit, D. (2010). Impuesto a la carne. Buenos Aires: Eterna Cadencia.

Esposito, R. (2005). Immunitas. Protección y negación de la vida. Amorrortu: Buenos Aires.

Esposito, R. (2009). Comunidad, inmunidad y biopolítica. Barcelona: Herder.

Foucault, M. (1994). Vigilar y castigar. Madrid: Siglo XXI.

Foucault, M. (1999a). Nacimiento de la medicina social. En Estrategias de poder. Obras esenciales, vol. II (pp. 363-384) (edición de J. Varela y F. Álvarez). Barcelona: Paidós.

Foucault, M. (1999b). ¿Crisis de la medicina o crisis de la antimedicina? En Estrategias de poder. Obras esenciales, vol. II (pp. 343-361) (edición de J. Varela y F. Álvarez). Barcelona: Paidós.

Foucault, M. (1999c). La política de la salud en el siglo XVIII. En Estrategias de poder. Obras esenciales, vol. II (pp. 327-342) (edición de J. Varela y F. Álvarez). Barcelona: Paidós.

Foucault, M. (2007a). El nacimiento de la clínica. Una arqueología de la mirada médica. Madrid: Siglo XXI.

Foucault, M. (2007b). La vida: la experiencia y la ciencia. En G. Giorgi y F. Rodríguez (Eds.), Ensayos sobre biopolítica. Excesos de vida (pp. 41-57). Buenos Aires: Paidós. 
Foucault, M. (2008). El nacimiento de la biopolítica. Buenos Aires: Fondo de Cultura Económica.

Foucault, M. (2012). Historia de la sexualidad I. La voluntad de saber. Madrid: Siglo XXI.

Gallo, R. (1987). Smallpox vaccine "triggered AIDS virus". The Times, 11 de mayo de 1987, Londres.

Haraway, D. (1995). Ciencia, cyborgs y mujeres. La reinvención de la naturaleza. Valencia: Cátedra y Universidad de Valencia.

Hardt, M., y Negri, A. (2002). Imperio. Barcelona: Paidós.

Illich, I. (1975). Némesis médica. La expropiación de la salud. Barcelona: Seix Barral.

Illich, I. (1993). Escribir la historia del cuerpo. Doce años después de Némesis médica. Archipiélago: Cuadernos de crítica de la cultura, 15, 87-93.

Illich, I. (1996). Patogénesis, inmunidad y calidad de la salud pública. Archipiélago: Cuadernos de crítica de la cultura, 25, 39-45.

Link, D. (2009). Fantasmas. Imaginación y sociedad. Buenos Aires: Eterna Cadencia.

López Petit, S. (2009). Breve tratado para atacar la realidad. Buenos Aires: Tinta Limón.

Neuman, A. (2012). Hablar solos. Madrid: Alfaguara.

Nilsson, L. (1985). The Body Victorious. The Illustrated Story or our Immune System and Other Defenses of the Human Body. New York: Delacorte.

Sloterdijk, P. (2001). Eurotaoísmo. Aportación a la crítica de la cinética política. Barcelona: Seix Barral.

Sontag, S. (1996). La enfermedad y sus metáforas. El sida y sus metáforas. Buenos Aires: Taurus.

Tauber, A. (1994). The Immune Self: Theory or Metaphor? New York: Cambridge University Press.

Treichler, P. A. (1987). AIDS, homophobia and biomedical discourse: An epidemic of signification, Cultural Studies, 1(3), 263-305. 